\title{
Computing Statistical Precision of Efficiency and Productivity Change Indices: A Bootstrap Application to Ghanaian Polytechnics
}

\begin{abstract}
Edwin Mends-Brew
Department of Mathematics and Statistics, Accra Polytechnic. Accra, Ghana Albert Ayi Ashiagbor
\end{abstract}

Department of Finance, University of Ghana Business School. Accra, Ghana

URL:http://dx.doi.org/10.19044/esj.2016.v12n9p273

\begin{abstract}
This study employs a bivariate smoothing bootstrap technique to obtain a statistical inference for Technical Efficiency and Malmquist Indices and their components of Polytechnics in Ghana over the period 2009-2014. The main contribution of this paper is to provide an Efficiency Analysis using a non-parametric approach with a robust estimator. This methodology is empirically being applied in the analysis of Polytechnic Education in Ghana because it affords us the opportunity to compute the statistical significance of changes in Polytechnics' Technical Efficiency and Productivity Indices and their respective components. Results showed that averagely, Technical Efficiency fluctuated over the period; however, Polytechnic Education experienced a significant technological regress, with few Polytechnics achieving increases in productivity led by improvements in efficiency. Policy implications are derived.
\end{abstract}

Keywords: Polytechnics; Data Envelopment Analysis; Efficiency; Productivity; Malmquist; Bootstrap; Statistical Precision

\section{Introduction}

Polytechnics are technological-based and knowledge institutions; their core objectives are to generate, acquire and transfer technological-based knowledge, and also to develop and transfer technology innovations. They support the economy as well by providing appropriate practical knowledge and skills demanded by the workforce in the Ghanaian economy and at the global market stage.

Efficiency in higher learning institutions refers to the extent to which institutions allocate efficiently the inputs available to generate the given level of output (Kipesha and Msigwa, 2013). Unlike economic efficiency which is 
measured through the combination of several inputs with one output, higher learning institutions' efficiency involves the combination of multiple inputs to produce multiple outputs (Johnes, 2006; Daghbashyan, 2009, 2011). This is due to the fact that these institutions produce multiple outputs such as the Educational and Research outputs from the combination of multiple inputs such as labour input (academic and nonacademic staff), government funds and noncurrent assets held by the institutions.

Generally, in examining how an ongoing development in Polytechnic Education management in Ghana could change, assessment of technical efficiency, productivity change over a period, including efficiency, scale and technology changes, are important determinants. Thus, there is a managerial and public policy need to better understand productive efficiencies of publicly owned Polytechnics in Ghana.

A glance at the efficiency and productivity literature in Ghana reveals some depressing concerns. It is evident that there is no study in the Ghanaian context that explicitly assesses the efficiency and productivity change of Tertiary Institutions particularly Polytechnic Education. This is however, not an indication that, studies on Polytechnic Education in Ghana are nonexistent. For instance, Nsiah-Gyabaah, (2005a) analysed the migration and brain drain and its implications for capacity building and institutional strengthening in Polytechnic Education in Ghana. Other studies on Polytechnic Education in Ghana include Agodzo and Songsore (2005), Nsiah-Gyabaah (2005 b), Afeti et al. (2003), and Aryeetey (2000).

A closer look at these studies has revealed that, none of them sufficiently addressed the measurement of productivity and efficiency change of Tertiary Education in Ghana. This study therefore seeks to contribute to filling these gaps.

The specific objective of the study is to establish a statistical precision measurement methodology for productivity and efficiency change of Polytechnics in Ghana based on the Application of Data Envelopment Analysis (DEA).

The empirical contribution of this paper should also be put into perspective. A study on measurement of productivity and efficiency change is limited especially in Sub-Saharan Africa. The application of statistical precision in measurement of dynamic change in the Tertiary Education sector with its peculiar characteristics is the added value of this paper. Additionally, considering the fact that the levels of efficiency and productivity changes in the Polytechnics are unknown, this study would also contribute in terms of policy prescriptions, to regulators and the management of strategic techniques that could be employed to improve the performance of Polytechnic Education in Ghana. 
The study is therefore significant in the sense that no previous study has distinctively carried out a similar methodological analysis on Polytechnic Education in Ghana. This raises questions about the workings of the Education System as far as its productivity and efficiency change are concerned. Orienting Educational Policies in the right direction would be improved by an understanding of the productivity sources and the identification of potential bottlenecks. Identifying the exact sources of productivity changes would allow the managers of Polytechnics and government to act on the specific needs (Essid et al, 2014).

The remainder of the paper is organized as follows: The ensuing section presents briefly an overview of the evolution of Polytechnic Education in Ghana. This is followed by a review of empirical literature pertaining to the study. Section 4 essentially deals with the discussion of the methodology employed in conducting the research. Results are subsequently presented and discussed in section 5. The paper ends with drawn conclusions in Section 6.

\section{The evolution of Polytechnic Education in Ghana}

The development of Polytechnic Education in Ghana is a checquered one. Since the pre-independence era till today, successive governments in Ghana have all emphasized the importance of formal Technical Education as a catalyst to rapid national development. This had led to the establishment of technical institutes in Accra, Takoradi and Kumasi in the 1950s to train the needed technicians for the accelerated development of the country.

By 1963, these technical institutes in Accra, Takoradi and Kumasi were re-designated as Polytechnics. However, these Polytechnics continued to operate essentially as non-tertiary, second-cycle institutions, offering mostly advanced craft courses and a few technician courses until in 1992 together with other Polytechnics in all the administrative regional capital of Ghana gained their tertiary status by virtue of the Polytechnic Act, (PNDCL 321 of 1992) which conferred on them the authority to award Higher National Diplomas (HNDs) and other certificates in a wide range of applied arts and science disciplines at sub-degree, degree and postgraduate degree levels.

The Polytechnic Law (Act 745 of 2007) which replaced the Polytechnic Act, (PNDCL 321 of 1992) clearly mandated the Polytechnics with clear aims and objectives as follows;

i) To provide Tertiary Education in the fields of manufacturing, commerce, science, technology, applied social sciences and applied arts, etc; and

ii) To provide opportunities for skills development, applied research and publication of research findings. The above clearly indicates that the central focus of Polytechnic Education in Ghana emphasizes on practicebased learning and the application of knowledge. The thrust of Polytechnic 
training is, therefore, on the acquisition of the relevant skills required to perform specific professional tasks without ignoring the underlying theoretical knowledge necessary for a proper understanding of the tasks to be performed.

In order for government to decide on a strategic approach to the establishment of the technical universities, the Ministry of Education set up a technical committee in September 2013 to develop a roadmap for the conversion of the Polytechnics to Technical Universities.

The proposed technical universities would contribute to raising the quality, competence and competitiveness of the Ghanaian workforce by providing opportunities for company employees to upgrade their skills and acquire new skills.

It is expected that the existing Polytechnics that fulfill the stated criteria by September, 2016, would be converted into Technical Universities.

\section{Related Literature}

A large part of the literature in this study exploits the use of linearprogramming based measures of efficiency along the lines of Charnes et al. (1978) and Fare et al. (1985), these methods have been termed Data Envelopment Analysis (DEA) and Malmquist Productivity Change index (MPI).

DEA, briefly, is a data-oriented, non-parametric linear programming method for evaluating the performance of a set of peer entities called decision making units within a group (e.g. a Polytechnic in Ghana), whose performance is characterized by multidimensional inputs and outputs (Charnes et al. 1978; Coelli, et al. 1999 ; Cooper et al. 2000; Gregoriou and Zhu , 2005).

A search of literature has revealed that DEA is by and large gaining attention for measuring efficiency and capacity in the Educational sector even though these studies are skewed towards the more advanced countries of the West (Glass et al. 1995; Avkiran, 2001; Flegg et al. 2004; Johnes, 2006a; 2006b; Worthington \& Lee, 2008; and Wolszczak-Derlacz and Parteka, 2010; 2011). For instance, Madden et al. (1997) assessed the efficiencies of economics departments in Australia universities. Johnes and Johnes (1993) assessed efficiencies of economics departments of UK universities in 1984-1988. Haksever and Muragishi (1998) and Colbert et al. (2000) studied the efficiency performance of MBA programmes in the USA. Tomkins and Green (1988) assessed cost efficiencies of UK accounting departments, whereas Beasley (1995) evaluated the efficiencies of chemistry and physics departments.

DEA has also been used to assess the level of efficiencies in different countries. Major ones include Ahn, Charnes \& Cooper (1988) on US 
universities in 1981-1985; Glass et al. (1995) on UK universities in 19891992; Avkiran (2001), Abbott and Doucouliagos (2003) and Carrington, et al. (2005) on universities in Australia.

The Malmquist productivity index which functions in the realm of panel data is a theoretical index, expressed in terms of distance functions defined on the true, but unknown, technology. In other words, a nonparametric Malmquist Index is an index that can compute productivity changes of a Polytechnic over time, in that it indicates progress or regress in efficiency along with progress or regress of the frontier technology under the multiple inputs and multiple outputs framework (Gregoriou and Zhu, 2005).

One advantage of DEA-based Malmquist Index is that it is possible to include multiple outputs in the analysis, which is particularly beneficial in Polytechnics as they employ multiple inputs and outputs.

There are few studies that applied the DEA and Malmquist techniques in the Educational Sector.

Flegg et al. (2004) applied a multi-period data envelopment analysis to measure efficiency of a sample of forty-five British universities for the period 1980/1981-1992/1993. Their results showed that total factor productivity increased by $51.5 \%$. However, a significant part of the rise was caused by an outward shift of the efficiency frontier (technological change) and not by the movement of universities towards the frontier (efficiency change). Nonetheless, this and other similar studies lack statistical inference.

The Bootstrap method for estimating confidence intervals of deterministic parameters could however, be applied to estimate confidence intervals for DEA-based Malmquist scores.

Fewer studies (Parteka \& Wolszczak-Derlacz, 2013; Essid et al. 2014) have applied this technique in the Educational Sector.

Essid et al. (2014) measured the productivity of high schools in Tunisia over the period 2000/2001-2003/ 2004 using Malmquist productivity index that took into account quasi-fixed factors which were decomposed into technical efficiency, scale efficiency and technological change. The application of this methodology to Tunisian high schools shows the high sensitivity to sample variations of the observed index changes and its components.

Parteka \& Wolszczak-Derlacz (2013) examined patterns of productivity change in a large set of 266 public Higher Education Institutions (HEIs) in seven European countries across the time period 2001-2005. It was found that a common 'European' frontier, HEI productivity rose on average by $4 \%$ annually.

It is evident that almost all previous studies focused on schools in the general university system. There is practically no study that has attempted to analyze the efficiency of polytechnics. As indicated earlier, it appears there 
is no study in the Ghanaian context that applies the nonparametric technique to analyse productivity and efficiency changes of Tertiary Institutions, especially Polytechnic Education. This paper therefore seeks to fill these gaps.

\section{Methodology}

This study uses three steps in its statistical analysis. The first step involves the computation of DEA efficiency scores. The following step requires the application of DEA-based Malmquist to compute Malmquist Productivity Indices and its components to establish performance changes over time, of each Polytechnic. Our third step looks at the application of bootstrapping algorithms in order to obtain appropriate statistical precision for the derived Efficiency and Productivity Indices.

\section{Data Source and Descriptions of the Input-Out Variables}

A balanced panel data for the period 2009/10-2013/14 academic periods were used based on data collected from the National Council for Tertiary Education (NCTE) and Ghana's Ministry of Education. In the application of DEA-based Malmquist techniques, the selection of right inputs and outputs are crucial. Input and output quantities of the Polytechnics as listed below are sets of data used to construct a piece-wise frontier over the data points. Efficiency and productivity change measures are then computed relative to this frontier that represents an efficient technology. Best-practice enjoins Polytechnics to determine the production frontier, that is, those that have the highest level of productive efficiency with given levels of inputs.

Available literature demonstrates the use of numerous input-output combinations. However, studies conclude that data availability, combined with the aims of the study, are the most significant determining factors in the final selection of input-output sets.

Polytechnics use such inputs as human resources (staff), students and financial resources and 'produce' at least two outputs, reflecting both their teaching and research missions.

The following input variables were used in our DEA-based Malmquist analysis; the number of staff and the number of HND students. These aspects of a polytechnic's activities were captured via the following output variables; the number of HND certificates awarded and the number of research publications in each respective polytechnic.

The general purpose statistical packages, $\mathrm{R}$ and FEAR (Frontier Efficiency Analysis with R) software were used for the empirical data analysis in this study. 


\section{Efficiency and Malmquist Productivity Indices Measurement}

The genesis of efficiency analysis was attributed to the work of Debreu (1951), Koopmans (1951) and Farrell (1957) who were the pioneers to measure empirically the efficiency of production units.

The DEA approach usually assumes that all Polytechnics, or more broadly, decision-making units within a sample have access to the same technology for the transformation of a vector of $\mathrm{N}$ inputs, denoted with $\mathrm{x}$, into a vector of $\mathrm{M}$ outputs, denoted with ' $\mathrm{y}$ '. This technology is described by a set $T \subseteq R_{+}^{M} x R_{+}^{N}$ as

$$
\psi=\left\{(x, y) \in R_{+}^{M} x R_{+}^{N}: x \in R_{+}^{N} \text { produces } y \in R_{+}^{M}\right\}
$$

This technology satisfies the following conventional assumptions:

Axiom 1: $\quad(0,0) \in \psi_{t},\left(0, y_{t}\right) \in \psi_{t} \Rightarrow y_{t}=0$ that is, no free lunch;

Axiom 2: the set $A\left(x_{t}\right)=\left(u_{t}, y_{t}\right) \in \psi_{t} ; u_{t} \leq x_{t}$ of dominating observations are bounded by $\forall x_{t} \in R_{+}^{N}$ that is, infinite outputs are not allowed with a finite input vector;

Axiom 3: $\quad \psi_{t}$ is closed;

Axiom 4: $\quad \forall\left(x_{t}, y_{t}\right) \in \psi_{t},\left(x_{t},-y_{t}\right) \leq\left(u_{t},-v_{t}\right) \Rightarrow\left(u_{t}, v_{t}\right) \in \psi_{t}$, that is, fewer outputs can always be produced with more inputs, and inversely (strong disposal of inputs and outputs);

Axiom 5: $\quad \psi_{t}$ is convex.

The frontier model used in this study follows an output-oriented assumption and can be derived for the $i^{\text {th }}$ Polytechnic by solving the following linear programming problem:

$\hat{\delta}_{i}=\max _{\hat{\delta}_{i}, \lambda}\left\{\delta>0 \mid \hat{\delta}_{i} y_{i} \leq \sum_{i=1}^{n} y_{i} \lambda ; x_{i} \geq \sum_{i=1}^{n} x_{i} \lambda ; \sum_{i=1}^{n} \lambda=1 ; \lambda \geq 0\right\}, i=1 \ldots n$ Polytechnics

where $\lambda$ is a $I x 1$ vector of constants. The value of $\hat{\delta}_{i}$ obtained is the technical efficiency score for the $i^{\text {th }}$ Polytechnic. A measure of $\hat{\delta}_{i}=1$ implies that the said Polytechnic is technically efficient, and inefficient if $\hat{\delta}_{i}>1$. This linear programming problem is solved $n$ times, for each Polytechnic in the sample.

The model can as well be estimated using either the Constant Returns to Scale (CRS) or Variable Returns to Scale (VRS) assumptions hence the shape of the frontier will differ depending on the scale assumptions that underline the model. In this paper we rely on the VRS assumption, as the CRS is only correct as long as it is appropriate to assume that firms are operating at an optimal level of scale. Technological advances, regulatory changes and internally generated activities might vary across the various 
Polytechnic in various size groups, so allowing for VRS would permit modeling of the entire range of technology.

The concept of Malmquist productivity index was first introduced by Malmquist (1953), and has further been studied and developed in the nonparametric framework by several authors including; Caves et al. (1982a;1982b), Fare and Grosskopf (1992), and Fare et al. (1989, 1992, 1994, 1997).

To measure the productivity change between two periods of time, we adopt the output-based Malmquist Index of Productivity developed by Fare et al. (1992, 1994, and 1997). We compute Malmquist Productivity Indices that are based on DEA scores, allowing us to measure the Malmquist Productivity change index of single Polytechnics between two data points $\mathrm{s}$ and $t$ :

$$
\operatorname{MPI}_{i}(s, t)=\left[\frac{d_{i}^{s}\left(x_{t}, y_{t}\right)}{d_{i}^{s}\left(x_{s}, y_{s}\right)} \mathrm{X} \frac{d_{i}^{t}\left(x_{t}, y_{t}\right)}{d_{i}^{t}\left(x_{s}, y_{s}\right)}\right]^{0.5}
$$

where $\mathrm{i}=1, \ldots, \mathrm{N}$ denotes the Polytechnic being evaluated, $x$ refers to inputs and $y$ to outputs, and MPI is the productivity of the most recent production point defined by inputs and outputs $\left(x_{t}, y_{t}\right)$ using period $t$ technology, relative to the earlier production point $\left(\mathrm{x}_{\mathbf{s}}, \mathrm{y}_{s}\right)$ using period $\mathrm{s}$ technology. Here, the MPI is defined as the geometric mean of two indices: the first, with period s, being the reference technology; the second, with period $\mathrm{t}$, being the reference technology. The geometric mean is used to avoid an arbitrary choice of the technologies from period $s$ or $t$ as $a$ reference. $\mathrm{d}^{\mathrm{t}}$ is the distance function measuring the efficiency of conversion of inputs $x_{t}$ to $y_{t}$ output during the period t.

In order to identify the source of growth in (2), we employ the Malmquist decomposition proposed by Fare et al. (1992) as follows:

$$
\operatorname{MPI}_{i}(s, t)=\left[\frac{d_{i}^{t}\left(x_{t}, y_{t}\right)}{d_{i}^{s}\left(x_{s}, y_{s}\right)} \text { EfficiencyChange(EC)}\right]\left[\frac{d_{i}^{s}\left(x_{t}, y_{t}\right)}{d_{i}^{t}\left(x_{t}, y_{t}\right)} \mathrm{X} \frac{d_{i}^{s}\left(x_{s}, y_{s}\right)}{d_{i}^{t}\left(x_{s}, y_{s}\right)}\right]^{0.5}
$$

The efficiency change, which can be further decomposed into scale efficiency and pure efficiency, indicates changes in the relative efficiency of a Polytechnic getting closer to or further away from the efficiency frontier. The technological change on the other hand measures the shift in the technology frontier itself and reflects the effects that characterize the Polytechnic Education System as a whole. The values of MPI, EC or TC greater (or less) than unity indicate a progress (regress) in productivity, for a Polytechnic between period s and $\mathrm{t}$. 


\section{The Bootstrap Algorithms for the DEA Efficiency Scores}

One main criticism, however, of the traditional DEA-based Malmquist Indices is that it does not have any statistical foundation, that is, it lacks statistical precision and does not permit us to determine whether changes in productivity, efficiency or technology are real, since the true production frontiers are unknown and for this reason must be estimated from a finite sample (Atkinson \& Wilson, 1995; Ferrier \& Hirschberg, 1997; Simar \& Wilson, 1998,1999, 2003; Lothgren, 1999; Odeck, 2009; Chowhury et al. 2014; Essid et al. 2014; Gharneh et al. 2014).

Thus, we employ a bivariate smoothing bootstrap estimation procedure for correcting and obtaining statistical precision or confidence intervals for the DEA, Malmquist Index and its components.

Bootstrapping is a widely used and powerful statistical tool that is based on the idea of re-sampling from an original data to assign statistical properties for the quantities of interest (Efron, 1979; Efron et al. 1993). Simar \& Wilson (1998) advocate that, problems that arise for bootstrapping in DEA models are best resolved by use of a smooth bootstrap procedure. In addition, the Malmquist Index uses panel data, with the possibility of temporal correlation. For this reason, Simar \& Wilson (1999) further modified the bootstrap algorithm for efficiency scores to preserve any temporal correlation present in the data by applying a bivariate smoothing procedure. The bootstrap algorithms for DEA efficiency scores and the Malmquist Indices can be summarized as follow:

1. Compute the efficiency scores $\hat{\theta}_{i}$ for each Polytechnic, by solving the linear programming problem (1) in the previous section.

2. Use kernel density estimation and the reflection method to generate a random sample of size $\mathrm{N}$

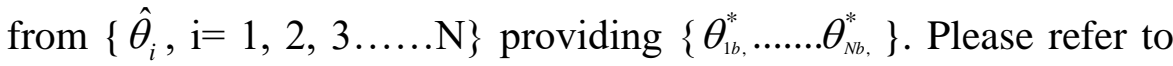
Simar \& Wilson (1998) for more technical details.

3. Compute a pseudo data set $\left\{\left(\left(x_{i b}^{*}, y_{i}\right), i=1,2,3, \ldots \ldots . N\right)\right\}$ to form the reference bootstrap technology.

4. For this pseudo data, compute the bootstrap estimate of efficiency $\hat{\theta}_{i b}^{*}$ of $\hat{\theta}_{i}$ for each $\mathrm{i}=1 \ldots \mathrm{N}$, by solving the bootstrap counterpart of the linear programming problem mentioned in the previous section.

5. Repeat steps $2-4$ a large number $B$ of times in order to provide a set of estimates

$\left\{\theta_{i b}^{*}, b=1, \ldots \ldots . . B\right\}$. We used 2000 bootstrap replications $(\mathrm{B}=2000)$ in obtaining the results. This provides us an adequate coverage of the confidence intervals. 
After computing these bootstrap estimates, it is important to note that statistical inferences could be made on the efficiency scores by constructing confidence intervals at desired levels of significance. Moreover, as the use of smoothed bootstrap guarantees that the bootstrap distribution will mimic the original sampling distribution of the estimators of the scores, obtaining bootstrap bias corrections for the scores is also easily dealt with. In particular, the bias of each estimation $\hat{\theta}_{i}$ could be estimated using the bootstrap sample as $\hat{\operatorname{bias}}_{i}\left(\hat{\theta}_{i}\right)=\bar{\theta}_{i}^{*}-\hat{\theta}_{i}$ where $\bar{\theta}_{i}^{*}=\frac{1}{B} \sum_{b=1}^{B} \hat{\theta}_{i b}^{*}$.

From this bootstrap estimation, the bias-corrected estimator for each efficiency score $\theta_{i}$ is obtained as $\tilde{\theta}_{i}=2 \hat{\theta}_{i}-\bar{\theta}_{i}^{*}$

This correction was deployed based on the comments by Simar \& Wilson (2000) and Efron et al. (1993) which indicate that the correction should not be used unless the following condition is satisfied; $\hat{\sigma}^{2}<\frac{1}{3}\left[\operatorname{bias}_{i}\left(\hat{\theta}_{i}\right)\right]^{2}, \quad$ where $\hat{\sigma}^{2}$ represents the sample variance of the bootstrap values.

These bias-corrected estimators are complementary to our main objective of explaining the efficiency of the Polytechnics. They could either confirm what the original scores revealed or express different efficiency behaviour.

\section{The Bootstrap Algorithms for the DEA-Based Malmquist Indices}

The procedure for bootstrapping productivity indices is based on the fact that the Malmquist index is a function of distance estimators. The methodology presented above for the efficiency scores can easily be adapted to this case, except that now the time-dependence structure of the data must be taken into account. The process is summarized as follows:

1. Compute the Malmquist Productivity Index $\hat{M}$ for each Polytechnic by solving the linear programming models in (1)

2. Compute a pseudo data set $\left\{\left(x_{i T}^{*}, y_{i T}^{*}\right), i=1, \ldots \ldots . N ; T=1,2\right\}$ to form the reference bootstrap technology using bivariate kernel density estimation and the adaption of the reflection method (See, Simar \& Wilson, 1999).

3. Compute the bootstrap estimate of the Malmquist Index for each Polytechnic $\hat{M}_{1 b}^{*}(s, t)$ by applying the original estimators to the pseudo sample obtained in step 2.

4. Repeat steps 2-3 a large number of times in order to provide a set of estimates 


$$
\left\{\hat{M}_{i 1}^{*}(s, t) \ldots . \hat{M}_{i B}^{*}(s, t)\right\} \text {. }
$$

Working in a similar manner as previously, these bootstrap estimates are used to perform statistical inferences on the productivity indices. Two complementary ways of doing this are through the development of an estimate of the bias and through the development of confidence intervals (Mooney and Duval, 1993).

With the information provided in the latter case, it is possible to ascertain whether productivity progress (or regress) measured by the Malmquist Productivity Index is significant, i.e., it is greater than (or less than) unity at the desired significance levels. The same holds for the sources of productivity, as it is now possible to assess the significance of both efficiency change and technical change, whenever they occur.

\section{Empirical Findings and Discussions}

Descriptive statistics for all input-output variables are found in Table 1. From this chart, it is observed that the standard deviations are relatively higher for all variables under consideration which demonstrates that large inequalities exist among the Polytechnics. This is an indication of how imperative it is for the Polytechnics to manage their inputs-outputs variables.

Table 1: Descriptive Statistics of Input-Output Variables

\begin{tabular}{ccccc}
\hline Variable & $\begin{array}{c}\text { Number of } \\
\text { Students }\end{array}$ & $\begin{array}{c}\text { Number } \\
\text { of staff }\end{array}$ & $\begin{array}{c}\text { Student } \\
\text { graduated }\end{array}$ & $\begin{array}{c}\text { Article } \\
\text { publication }\end{array}$ \\
\hline Mean & 4892.64 & 234.70 & 1276.14 & 22.20 \\
Median & 4482.50 & 232.50 & 1158.00 & 22.00 \\
Standard Dev & 2642.99 & 92.83 & 730.89 & 5.11 \\
Minimum & 999.00 & 120.00 & 166.00 & 14.00 \\
Maximum & 9984.00 & 400.00 & 2600.00 & 35.00 \\
\hline
\end{tabular}

Table 2: Bootstrap Estimates (Annual Average)

\begin{tabular}{cccccc}
\hline Year & $\begin{array}{c}\text { Estimated } \\
\text { Eff }\end{array}$ & $\begin{array}{c}\text { Bias- } \\
\text { Corrected }\end{array}$ & Bias & \multicolumn{2}{c}{ Confidence interval } \\
& & & & $\begin{array}{c}\text { Lower } \\
\text { Bound }\end{array}$ & $\begin{array}{c}\text { Upper } \\
\text { Bound }\end{array}$ \\
\hline $2009 / 2010$ & 0.69920 & 0.61772 & 0.08148 & 0.55932 & 0.69055 \\
$2010 / 2011$ & 0.81641 & 0.72893 & 0.08749 & 0.65498 & 0.80792 \\
$2011 / 2012$ & 0.79931 & 0.70066 & 0.09865 & 0.61881 & 0.79006 \\
$2012 / 2013$ & 0.77051 & 0.68229 & 0.08823 & 0.59907 & 0.76224 \\
$2013 / 2014$ & 0.84638 & 0.71750 & 0.12888 & 0.61682 & 0.83553 \\
Average & 0.786362 & 0.68942 & 0.09694 & 0.60980 & 0.77726 \\
\hline
\end{tabular}

Table 2 summarises annual mean efficiency for Polytechnic Education over the period 2009/2010-2013/2014. Column 2 lists the mean efficiency estimates, and columns 3 through to 6 list the bias-corrected estimates, the bootstrap bias estimates and the efficiency's lower and upper 
bounds for the $95 \%$ confidence intervals(annual means), respectively, for each year.

Moreover, Table 2 shows that although Polytechnic Education is inefficient in the overall number of years, the sector's efficiency level improved over the period 2013/2014. Note that in all cases the mean of the estimated efficiency lies to the right of the estimated confidence intervals. This result reflects the theory behind the construction of the confidence intervals presented by Simar \& Wilson (1998b).

Additionally, the estimates of technical efficiency differ from the bias-corrected estimates. In some periods this difference (the bias) is quite small. For instance, the average difference was 0.0969 .

The means of the estimated confidence intervals, which define the statistical location of the true efficiency, were quite narrow over the periods. The minor bias of VRS estimates and the relatively smaller confidence intervals in these years imply that the results are relatively stable. However, results from this table are very general and do not facilitate the distinction between the performance of individual polytechnics. Hence, the bootstraps of the efficiency scores for individual Polytechnics (hereafter denoted as P1, P2...P10) displayed in Table 3.

Table 3: Bootstrap Efficiency Scores, 2009/2010-2013/2014 Academic Years.

\begin{tabular}{ccccccc}
\hline $\begin{array}{c}\text { Academic } \\
\text { Year }\end{array}$ & Polytechnic & $\begin{array}{c}\text { Estimated } \\
\text { Eff }\end{array}$ & $\begin{array}{c}\text { Bias- } \\
\text { Correcte } \\
\text { d }\end{array}$ & Bias & \multicolumn{2}{c}{ Confidence interval } \\
& & & & $\begin{array}{c}\text { Lower } \\
\text { Bound }\end{array}$ & $\begin{array}{c}\text { Upper } \\
\text { Bound }\end{array}$ \\
\hline $2009 / 2010$ & P1 & 0.67531 & 0.59331 & 0.08121 & 0.52918 & 0.66723 \\
$2009 / 2010$ & P2 & 0.34302 & 0.31867 & 0.02435 & 0.29908 & 0.33893 \\
$2009 / 2010$ & P3 & 0.45973 & 0.40062 & 0.05910 & 0.35736 & 0.45467 \\
$2009 / 2010$ & P4 & 0.87765 & 0.80249 & 0.07516 & 0.73439 & 0.86609 \\
$2009 / 2010$ & P5 & 1.00000 & 0.83416 & 0.16584 & 0.73834 & 0.98745 \\
$2009 / 2010$ & P6 & 0.48377 & 0.43857 & 0.04521 & 0.40242 & 0.47696 \\
$2009 / 2010$ & P7 & 0.50805 & 0.48589 & 0.02216 & 0.45844 & 0.50466 \\
$2009 / 2010$ & P8 & 0.64445 & 0.58062 & 0.06383 & 0.53445 & 0.63644 \\
$2009 / 2010$ & P9 & 1.00000 & 0.86536 & 0.13464 & 0.77905 & 0.98871 \\
$2009 / 2010$ & P10 & 1.00000 & 0.85750 & 0.14251 & 0.76058 & 0.98438 \\
$2010 / 2011$ & P1 & 1.00000 & 0.84876 & 0.15124 & 0.74102 & 0.98296 \\
$2010 / 2011$ & P2 & 0.38055 & 0.34642 & 0.03412 & 0.31659 & 0.37574 \\
$2010 / 2011$ & P3 & 0.80058 & 0.69921 & 0.10137 & 0.61096 & 0.79176 \\
$2010 / 2011$ & P4 & 1.00000 & 0.81429 & 0.18571 & 0.70711 & 0.98854 \\
$2010 / 2011$ & P5 & 0.99049 & 0.92983 & 0.06066 & 0.86289 & 0.98203 \\
$2010 / 2011$ & P6 & 0.80405 & 0.72551 & 0.07846 & 0.65158 & 0.79672 \\
$2010 / 2011$ & P7 & 0.66601 & 0.61925 & 0.04675 & 0.57447 & 0.65687 \\
$2010 / 2011$ & P8 & 0.59217 & 0.52143 & 0.07074 & 0.46991 & 0.58706 \\
$2010 / 2011$ & P9 & 1.00000 & 0.91127 & 0.08873 & 0.82166 & 0.99130 \\
$2010 / 2011$ & P10 & 0.93023 & 0.87319 & 0.05704 & 0.79356 & 0.92619 \\
$2011 / 2012$ & P1 & 1.00000 & 0.80260 & 0.19741 & 0.66434 & 0.98802 \\
$2011 / 2012$ & P2 & 0.52171 & 0.45197 & 0.06973 & 0.39296 & 0.51554 \\
\hline
\end{tabular}




\begin{tabular}{lcccccc}
\hline $2011 / 2012$ & P3 & 1.00000 & 0.78287 & 0.21713 & 0.61506 & 0.98306 \\
$2011 / 2012$ & P4 & 0.66747 & 0.59026 & 0.07721 & 0.51843 & 0.65874 \\
$2011 / 2012$ & P5 & 0.99960 & 0.88564 & 0.11396 & 0.81189 & 0.98479 \\
$2011 / 2012$ & P6 & 0.66041 & 0.58887 & 0.07155 & 0.52734 & 0.65407 \\
$2011 / 2012$ & P7 & 0.64641 & 0.60476 & 0.04165 & 0.56184 & 0.63909 \\
$2011 / 2012$ & P8 & 0.56728 & 0.50895 & 0.05833 & 0.46528 & 0.55964 \\
$2011 / 2012$ & P9 & 1.00000 & 0.92384 & 0.07616 & 0.84022 & 0.99338 \\
$2011 / 2012$ & P10 & 0.93023 & 0.86683 & 0.06340 & 0.79076 & 0.92431 \\
$2012 / 2013$ & P1 & 1.00000 & 0.78061 & 0.21937 & 0.61546 & 0.98326 \\
$2012 / 2013$ & P2 & 0.69301 & 0.61156 & 0.08144 & 0.54674 & 0.68484 \\
$2012 / 2013$ & P3 & 0.84559 & 0.71851 & 0.12709 & 0.58861 & 0.83438 \\
$2012 / 2013$ & P4 & 0.78573 & 0.67479 & 0.11094 & 0.57102 & 0.77558 \\
$2012 / 2013$ & P5 & 0.99661 & 0.88372 & 0.11289 & 0.76583 & 0.98706 \\
$2012 / 2013$ & P6 & 0.41573 & 0.39411 & 0.02162 & 0.36736 & 0.41241 \\
$2012 / 2013$ & P7 & 0.57687 & 0.53853 & 0.03833 & 0.50312 & 0.57072 \\
$2012 / 2013$ & P8 & 0.46138 & 0.42317 & 0.03822 & 0.39869 & 0.45394 \\
$2012 / 2013$ & P9 & 1.00000 & 0.92475 & 0.07525 & 0.84063 & 0.99395 \\
$2012 / 2013$ & P10 & 0.93023 & 0.87313 & 0.05711 & 0.79319 & 0.92626 \\
$2013 / 2014$ & P1 & 1.00000 & 0.78779 & 0.21221 & 0.61743 & 0.98479 \\
$2013 / 2014$ & P2 & 1.00000 & 0.85008 & 0.14992 & 0.74184 & 0.98504 \\
$2013 / 2014$ & P3 & 1.00000 & 0.84371 & 0.15629 & 0.68891 & 0.98765 \\
$2013 / 2014$ & P4 & 1.00000 & 0.81119 & 0.18880 & 0.67675 & 0.98582 \\
$2013 / 2014$ & P5 & 1.00000 & 0.83991 & 0.16009 & 0.72439 & 0.98622 \\
$2013 / 2014$ & P6 & 0.41705 & 0.39172 & 0.02533 & 0.36030 & 0.41455 \\
$2013 / 2014$ & P7 & 0.59691 & 0.54151 & 0.05541 & 0.50243 & 0.58941 \\
$2013 / 2014$ & P8 & 0.44984 & 0.41825 & 0.03159 & 0.38613 & 0.44557 \\
$2013 / 2014$ & P9 & 1.00000 & 0.85322 & 0.14678 & 0.73949 & 0.98939 \\
$2013 / 2014$ & P10 & 1.00000 & 0.83764 & 0.16236 & 0.73049 & 0.98683 \\
\hline & & & & & &
\end{tabular}

Table 3 presents the bootstrapped DEA-VRS results, estimated for the period between 2009/10 and 2013/14. The paper supports the work done by Simar \& Wilson (1999) and we used 2000 bootstrap replications (B = 2000) in obtaining the results. According to the authors this should provide an adequate coverage of the confidence intervals.

A cursory look at the results indicates that the original DEA estimates lie for every Polytechnic outside the estimated confidence intervals, while the bootstrapped DEA estimates lie for every Polytechnic inside the confidence interval. Such problems are due to the bias in the original estimates, and it is the main reason why the bootstrapped DEA are preferred to the original estimates.

It is evident from the third column in Table 3 that technical efficiency fluctuates along the periods among Polytechnics and none of the Polytechnics retains its position on the frontier of best practices across all years except P9. However, when taken into consideration the bootstrapped efficiency scores, it is clear that none of the Polytechnics is close to being fully efficient, even though efficiency increases along the period. Additionally, the bootstrapped efficiency scores are lower than the standard 
efficiency scores, mainly due to the bias in the original DEA, which was previously discussed.

Table 4: $\quad$ Estimates of Malmquist Indexes (change in productivity) .

\begin{tabular}{|ccccc|}
\hline Polytechnic & $2009 / 2010-$ & $2010 / 2011-$ & $2011 / 2012-$ & $2012 / 2013-$ \\
& $2010 / 2011$ & $2011 / 2012$ & $2012 / 2013$ & $2013 / 2014$ \\
\hline P1 & $1.24288^{* *}$ & $1.07404^{* *}$ & $0.82689^{* *}$ & $0.88184^{* *}$ \\
P2 & $1.18846^{* *}$ & $1.26883^{*}$ & $0.98791^{*}$ & $1.15743^{* *}$ \\
P3 & $1.22112^{* *}$ & $1.09123^{* *}$ & $0.82090^{* *}$ & $1.03575^{*}$ \\
P4 & $1.20379^{* *}$ & $0.69362^{* *}$ & $1.02657 * *$ & $1.04609 * *$ \\
P5 & $0.91159^{*}$ & $1.14887^{* *}$ & 0.91859 & $1.09983^{* *}$ \\
P6 & $1.64111^{* *}$ & $0.82687^{* *}$ & $0.36511^{* *}$ & $0.90819^{* *}$ \\
P7 & $1.50912^{* *}$ & $0.9502^{* *}$ & $0.83634^{* *}$ & $1.07657^{* *}$ \\
P8 & $0.8960^{* *}$ & $1.08747^{*}$ & $0.75324 * *$ & $0.77206^{* *}$ \\
P9 & $0.84118^{* *}$ & $1.10124^{* *}$ & $0.95976^{* *}$ & $1.31235^{* *}$ \\
P10 & $0.90659^{* *}$ & $1.045^{* *}$ & $0.92804 * *$ & $1.44166^{* *}$ \\
G. mean & 1.12849 & 1.01541 & 0.81516 & 1.05677 \\
\hline
\end{tabular}

Note: Numbers greater than unity indicate progress and those less than unity indicate regress.

Single asterisk $(*)$ denotes significant differences from unity at $90 \%$; double asterisk $(* *)$ denotes significant from unity at $95 \%$.

Table 4 presents the original MPI estimates and the statistical testing results of productivity changes for Polytechnics over two pairs of academic years between 2009/10 and 2013/14. Table 4 further illustrates that different conclusions could be drawn based on the original MPI estimates and their bootstrapping results. The original MPI estimates indicate that all the Polytechnics have a change (most likely an improvement) in their total factor performance for each consecutive two-year academic period. Almost all of the estimates are significantly different from unity at the 0.10 or 0.05 level of significance except P5 which is insignificantly different from unity, for the years; (2011/2012-2012/2013). In addition, we observe that none of the Polytechnics maintains consistency in improvement in productivity throughout the period.

During the academic period of 2009/2010-2010/2011, 60\% of the Polytechnics under consideration showed moderate progress, resulting in an average productivity gain of $13 \%$ for the period.

In the period 2010/2011-2011/2012 the results indicate productivity gains for $70 \%$ of Polytechnics and significant decreases in productivity for the remaining $30 \%$. This results in an average productivity of $2 \%$ for the period.

The results for the academic periods 2011/2012-2012/2013, however, were quite different. All Polytechnics but one showed productivity loss. P6 which showed the highest level of productivity progression in 2009/20102010/2011 exhibited a 63\% productivity loss in 2011/2012-2012/2013. 
Averagely, Polytechnic Education showed a significant decrease in productivity of about $19 \%$ during this period.

Remarkably, during the academic periods of 2012/2013-2013/2014, all the ten Polytechnics exhibited a certain level of improvement compared with the preceding academic period resulting in an average productivity progression of 5.6\%. This improvement could be viewed and interpreted as a responds by the Polytechnics, keenly working progressively towards the attainment of the conversion target set by the Ministry of Education to upgrade Polytechnics that satisfy the set criterion before 2016 into technical universities.

Predictably, Polytechnic Education averagely showed a $0.32 \%$ productivity loss (i.e., 0.99676 productivity change) over the periods 2009/2010-2013/2014.

Expectedly, having decomposed the MPI estimates (including their bootstrapping results) into their efficiency change and technological change components using Eq. (3), the main causes of the productivity change over the period, could be traced. As stated earlier, the efficiency change component measures the catch-up effect, which reflects the change in relative performance with regard to Polytechnics' production frontiers at period $\mathrm{t}$ and $\mathrm{s}$.

Table 5 shows the efficiency change components obtained. Two polytechnics, namely P5, and P9, did not experience changes in their technical efficiency over the period. Based on the bootstrapping results, we might conclude that technical efficiency change is also not significant for P10. Generally, the efficiency changes of the Polytechnics dwindled over the period.

Table 5: The Efficiency Change Components of MPI from 2009/2010-2013/2014

\begin{tabular}{|c|c|c|c|c|}
\hline Polytechnic & $\begin{array}{c}2009 / 10- \\
2010 / 11\end{array}$ & $2010 / 11-2011 / 12$ & $\begin{array}{c}2011 / 12- \\
2012 / 13\end{array}$ & $\begin{array}{c}2012 / 13- \\
2013 / 14\end{array}$ \\
\hline P1 & $1.56058^{* *}$ & 1.01367 & 1.00000 & 0.93295 \\
\hline P2 & $1.17516^{* *}$ & $1.32338^{* *}$ & $1.26117^{* *}$ & 0.99366 \\
\hline P3 & $1.29653^{* *}$ & $1.29868^{* *}$ & 1.08381 & 0.90894 \\
\hline P4 & $1.00331^{* *}$ & $0.76939^{* *}$ & 1.06841 & 0.89807 \\
\hline P5 & 1.00000 & 1.00000 & 1.00000 & 1.00000 \\
\hline P6 & $1.54144^{*}$ & $1.16551^{*}$ & $0.48750^{* *}$ & 0.83942 \\
\hline P7 & $1.38412^{* *}$ & $1.26118^{* *}$ & 1.06768 & 0.92424 \\
\hline P8 & $0.88350^{* *}$ & 1.02389 & 0.91561 & $0.66587 * *$ \\
\hline P9 & 1.00000 & 1.00000 & 1.00000 & 1.00000 \\
\hline P10 & 1.05328 & 0.92614 & 0.98466 & 1.09657 \\
\hline G. mean & $\mathbf{1 . 1 6 8 2 7}$ & $\mathbf{1 . 0 6 4 5 1}$ & $\mathbf{0 . 9 6 2 9 1}$ & $\mathbf{0 . 9 1 8 7 8}$ \\
\hline
\end{tabular}

* The efficiency change component is significantly different from unity at the 0.10 level.

** The efficiency change component is significantly different from unity at the 0.05 level. 
The technological change component measures the frontier-shift effect, which quantifies the shift in the production technology of Polytechnic ' $i$, over time from period $s$ to period $t$.

Table 6 shows the results of the technological change components. Out of the 40 entries, the original estimates showed that 21 registered negative shift in technology. The bootstrap results, however, revealed that only four were significantly greater than unity. The results also showed significant technological regress in most of the entries. That is, a greater number of Polytechnics were found to register a negative shift in technology. For instance, during the period 2011/2012-2012/2013, the entire sector, on average, experienced a regress in technology of about $15 \%$.

Table 6: Technological Change Component of MPI from 2009/2010 to 2013/2014

\begin{tabular}{|c|c|c|c|c|}
\hline Polytechnic & $\begin{array}{c}2009 / 10- \\
2010 / 11\end{array}$ & $\begin{array}{c}2010 / 11- \\
2011 / 12\end{array}$ & $\begin{array}{c}2011 / 12- \\
2012 / 13\end{array}$ & $2012 / 13-2013 / 14$ \\
\hline P1 & $0.796418^{*}$ & 1.059576 & $0.826887^{* *}$ & 0.945213 \\
\hline P2 & 1.011319 & 0.958775 & $0.78333^{* *}$ & 1.164822 \\
\hline P3 & 0.941839 & $0.840266^{* *}$ & $0.757423^{* *}$ & 1.139516 \\
\hline P4 & 1.199811 & $0.90152^{* *}$ & 0.960836 & 1.164822 \\
\hline P5 & $0.911588^{*}$ & $1.148872^{* *}$ & 0.918595 & 1.099829 \\
\hline P6 & 1.064664 & $0.709448^{* *}$ & $0.748945^{* *}$ & 1.081915 \\
\hline P7 & 1.090314 & $0.753423^{* *}$ & $0.78333^{* *}$ & 1.164822 \\
\hline P8 & 1.014157 & 1.062096 & $0.822663^{* *}$ & 1.159475 \\
\hline P9 & $0.84118^{* *}$ & 1.101244 & 0.959762 & $1.312351^{*}$ \\
\hline P10 & $0.860736^{* *}$ & $1.12833^{* *}$ & 0.942505 & $1.314699^{* *}$ \\
\hline G. mean & $\mathbf{0 . 9 6 5 9 5}$ & $\mathbf{0 . 9 5 3 8 8 4}$ & $\mathbf{0 . 8 4 6 5 5 8}$ & $\mathbf{1 . 1 5 0 1 8 7}$ \\
\hline
\end{tabular}

*The technological change component is significantly different from unity at the 0.10 level.

**The technological change component is significantly different from unity at the 0.05 level.

Using the four components explained in section 4, we could trace the main causes of the productivity change over the sample period. The breakdown of the scores for the change in technical efficiency into pure technical efficiency and scale efficiency change shows mixed results, with some Polytechnics obtaining simultaneous gains in both areas whilst others made gains in only one, which signifies an improvement in managerial skills. This shows that there were investments in organizational factors associated with best-practice initiatives, more accurate reporting and improvement in quality.

Table 7 details estimated changes in pure efficiency for consecutive years. Out of the 40 estimates of changes in pure efficiency, only 18 estimates differed from unity and 6 were statistically significant. A number of Polytechnics showed no change in pure efficiency for all reported years (P3, P4, P5 and P9). Polytechnic Education, on average, exhibited oscillating 
changes in technical efficiency as a result of possible inappropriate policy implementation.

Table 7: Pure Efficiency Change Component of MPI from 2009/2010 to 2013/2014

\begin{tabular}{|c|c|c|c|c|}
\hline Polytechnic & $\begin{array}{c}2009 / 10- \\
2010 / 11\end{array}$ & $2010 / 11-2011 / 12$ & $2011 / 12-2012 / 13$ & $\begin{array}{c}2012 / 13- \\
2013 / 14\end{array}$ \\
\hline P1 & 1 & 1 & 1 & 1 \\
\hline P2 & 0.980748 & $1.095008^{* *}$ & 1.02438 & 1 \\
\hline P3 & 1 & 1 & 1 & 1 \\
\hline P4 & 1 & 1 & 1 & 1 \\
\hline P5 & 1 & 1 & 1 & 1 \\
\hline P6 & 0.985982 & $1.146526^{* *}$ & $0.5249^{* *}$ & $1.23795^{* *}$ \\
\hline P7 & 1.026965 & $1.17264^{* *}$ & $1.11957 * *$ & 0.9644 \\
\hline P8 & 0.959 & 0.970907 & $0.807754^{* *}$ & 0.92275 \\
\hline P9 & 1 & 1 & 1 & 1 \\
\hline P10 & 1 & 0.9401 & 0.995001 & 1.069061 \\
\hline G. mean & $\mathbf{0 . 9 9 5 1 3}$ & $\mathbf{1 . 0 2 9 9 8 7}$ & $\mathbf{0 . 9 2 9 9 7}$ & $\mathbf{1 . 0 1 6 4 9 4}$ \\
\hline
\end{tabular}

Table 9: Number of Polytechnics experiencing MPI, efficiency, technological pure efficiency and scale efficiency changes based on the original and bootstrapping results

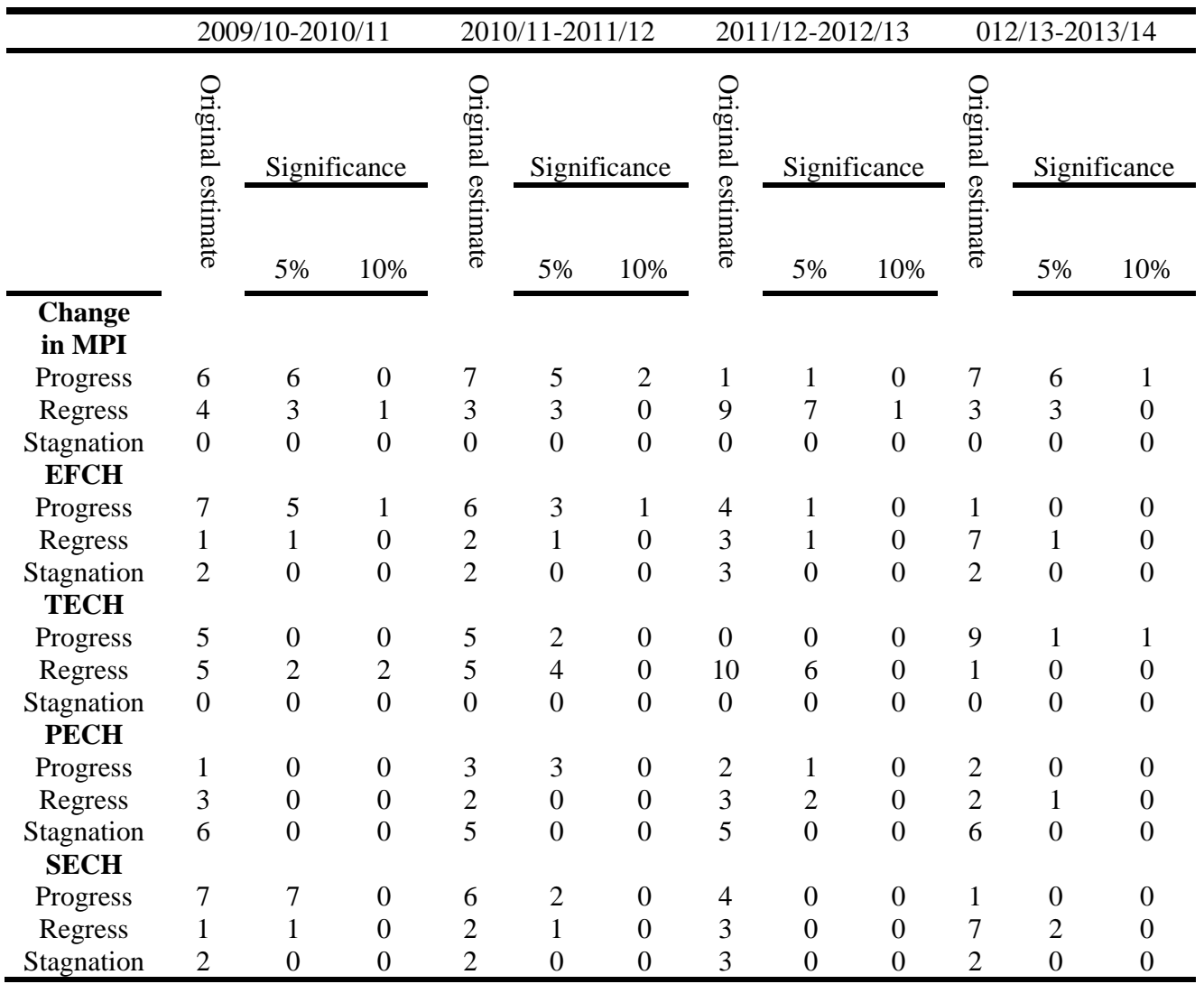


Table 8 reveals the estimated changes in scale efficiency and it is evident that majority of the changes from unity are statistically significant. The results for 2009/10-2010/11 and 2011/12-2012/13 recorded significant progression in their scale efficiency. This phenomenon is possibly attributed to government huge investment in Polytechnic Education in the country over the periods. Over these three periods most of the Polytechnics experienced positive changes in scale efficiency (i.e. the estimates are greater than unity) or very low levels of negative changes.

Table 8: Scale Efficiency Change Component of MPI from 2009/2010 to 2013/2014

\begin{tabular}{|l|l|l|l|l|}
\hline Polytechnic & $2009 / 10-2010 / 11$ & $\begin{array}{l}2010 / 11- \\
2011 / 12\end{array}$ & $\begin{array}{l}2011 / 12- \\
2012 / 13\end{array}$ & $2012 / 13-2013 / 14$ \\
\hline P1 & $1.560583 * *$ & 1.013648 & 1 & 0.932952 \\
\hline P2 & $1.198227 * *$ & $1.208559 * *$ & 1.23115 & 0.993658 \\
\hline P3 & $1.296531^{* *}$ & $1.298678^{* *}$ & 1.083807 & 0.908941 \\
\hline P4 & 1.003315 & $0.769393 * *$ & 1.068414 & 0.898068 \\
\hline P5 & 1 & 1 & 1 & 1 \\
\hline P6 & $1.563353^{* *}$ & 1.016557 & 0.928755 & $0.678076^{* *}$ \\
\hline P7 & $1.347776^{* *}$ & 1.075502 & 0.953649 & 0.958357 \\
\hline P8 & $0.921266^{* *}$ & 1.054567 & 1.133523 & $0.721611^{* *}$ \\
\hline P9 & 1 & 1 & 1 & 1 \\
\hline P10 & $1.053275^{* *}$ & 0.985155 & 0.989604 & 1.025733 \\
\hline G. mean & $\mathbf{1 . 1 7 3 9 9}$ & $\mathbf{1 . 0 3 3 5 0 5}$ & $\mathbf{1 . 0 3 5 4 2 4}$ & $\mathbf{0 . 9 0 3 8 7 5}$ \\
\hline
\end{tabular}

Over the period 2012/13-2013/14, the results worsened with only one Polytechnic showing some improvements in scale efficiency (i.e. P10). Other Polytechnics either experienced negative change or kept their scale efficiency relatively unchanged (such as P5 and P9).

These results, in conjunction with those for changes in pure efficiency, indicate that considerable changes in Polytechnics' productivity for the period 2011/12-2012/13 cannot be attributed to efficiency change components (pure efficiency change nor scale efficiency change); they could be explained only by technological changes. Additionally, the decline in productivity change during the period 2012/13-2013/2014 is only attributable to scale efficiency change.

\section{Conclusion and Recommendations:}

We conclude this section by summarizing the significance levels in terms of growth, decline and stagnation of the findings from the bootstrapping results of MPI change and its components for the entire period from 2009 to 2014 in Table 9. Although a number of Polytechnics were found to have experienced changes in MCPI, efficiency and technological change, effects based on the original estimates, are not significant in most 
cases. Thus, the performance comparisons among Polytechnics based on the original MPI estimates need to be interpreted with caution.

Polytechnic Education was largely inefficient overall during the review period, even though, the sector's efficiency level improved over the period 2013/2014. Particularly, the technical efficiency amongst the Polytechnics fluctuates along the periods and none retains its position on the frontiers of best practices across the years except P9. However, when taken into consideration the bootstrapped efficiency scores, it is evident that none of the Polytechnics is close to being fully efficient, even though, along the period the efficiency increases.

We also observe that none of the Polytechnics maintains consistent improvement in productivity change throughout the sampled period. Averagely, the efficiency change of the Polytechnics dwindled over the entire period. Specifically, most Polytechnics registered negative shifts in technology.

The breakdown of the scores for the change in technical efficiency into pure technical efficiency and scale efficiency change shows mixed results. While some Polytechnics obtained simultaneous gains in both areas, others made gains in only one. This signifies an improvement in managerial skills; indicative of the fact that, there were investments in organizational factors associated with best-practice initiatives, more accurate reporting and ultimately, improvement in quality.

Polytechnic Education in Ghana, on average, showed oscillating changes in technical efficiency as a result of possible implementation of inappropriate policies.

These results, in conjunction with those for changes in pure efficiency, indicate that considerable changes in Polytechnic productivity for the period cannot be attributed to efficiency change components (pure efficiency change nor scale efficiency change); they are explained only by technological changes. Additionally, the deterioration in productivity change during the period is attributable to scale efficiency change.

Although a number of Polytechnics were found to experience changes in MCPI, efficiency and technological change effects based on the original estimates, were not significant in most cases. Therefore, the performance comparisons among Polytechnics based on the original MPI estimates need to be interpreted with caution.

Moreover, considering the fact that, the levels of efficiency and productivity change in the Polytechnics are now scientifically and empirically computed, policy makers, regulators and Management are advised to implement strategies that could help improve the performance of Polytechnic Education in Ghana. 
To conclude, this study has identified the exact sources of productivity change in Polytechnic Education in Ghana. It is hoped that Management of Polytechnics and the Government would adequately act on the specific needs by the orientation of educational policies in the right direction.

\section{References:}

Abbott, M \& Doucouliagos, C (2003). The efficiency of Australian universities: A data envelopment analysis. Economics of Education Review,. 22 (1) 89-97.

Afeti, G., Baffour-Awuah, D. \& Budu-Smith, J. (2003). Baseline Survey for the introduction of competency-based training in Polytechnics. National Council for Tertiary Education (NCTE) and Japan International Cooperation Agency (JICA), Accra.

Agodzo, S. K. \&Songsore, J. (2005). Competency-based learning: The case of Wa Polytechnic, Journal of Polytechnics in Ghana.1(1)1-8.

Ahn T., Charnes A., \& Cooper W.W. (1988). Some statistical and DEA evaluations of relative efficiencies of public and private institutions of higher learning; Socio-Economic Planning Sciences22; 259-69.

Aryeetey, E. (2000). A Diagnostic study of research and technology development in Ghana, ISSER Technical Publication No. 60, Accra.

Atkinson, S. E, \& Wilson, P.W. (1995). Comparing mean efficiency and productivity scores from small samples: a bootstrap methodology. Journal of Productivity Analysis 6:137-52.

Avkiran, N.K. (2001). Investigating technical and scale efficiencies of Australian Universities through data envelopment analysis Socio-Economic Planning Sciences 35 57-80

Beasley J.E. (1995), Determining teaching and research efficiencies; Journal of the Operational Research Society46(4); 441-52.

Carrington, R., T. Coelli \& P. Rao. (2005). The performance of Australian universities: conceptual issues and preliminary results. Economic Papers 24, 145-63.

Charnes, A., Cooper, W.W., \& Rhodes, E. (1978).Measuring the inefficiency of decision making units. European Journal of Operational Research, 2, 429444.

Coelli, T., Rau, D.D.P. \&Battese, G.E. (1999.) An introduction to efficiency and productivity analysis (Kluwer: Academic Publishers, Boston).

Colbert, A., Levary, R.R. \& Shaner. M.C. (2000). Determining the relative efficiency of MBA programs using DEA. European Journal of Operational Research 125: 656-669. 
Cooper, W.W., Seiford, L.M. \& Tone, K. (2000) Data envelopment analysis. A comprehensive text with models, applications, references and DEA-solver Software (Kluwer Academic Publishers)

Daghbashya., Z. (2009). Do university units differ in the efficiency of resource utilization? Working Paper Series in Economics and Institutions of Innovation, No, 176, Royal Institute of Technology, CESIS.

Daghbashyan, Z. (2011). The economic efficiency of Swedish higher Education institutions. CESIS Electronic Working Paper Series Paper No. 245, Division of Economics, CESIS, KTH: The Royal Institute of technology Centre of Excellence for Science and Innovation Studies (CESIS).

Essid, H., Ouellette, P. \& Vigeant, S. (2014). Productivity, efficiency, and technical change of Tunisian schools: a bootstrapped Malmquist approach with quasi-fixed inputs. Omega 42: 88-97

Fare, R., Grosskopf, S., \& Lovell, C.A.K. (1985). The measurement of efficiency of production, Boston: Kluwer-Nijhoff Publishing.

Fare R, Grosskopf S, Lindgren B, Roos P (1992) Productivity changes in Swedish pharmacies 1980-1989: a nonparametric approach. Journal of Productivity Analysis 3:85-101

Fare R, Grosskopf S, Norris M,\& Zhang Z (1994) Productivity growth, technical progress and efficiency changes in industrialized countries. Am Econ Rev 84:66-83

Fare R, Griffell-Tajte E, Grosskopf S, \&Knox Lovell CA (1997) Biased technical change and Malmquist productivity index. Scand J Econ 99:119127

Farrell, M.J. (1957). The measurement of productive efficiency. Journal of Royal Statistical Society A 120:253-281

Ferrier, G. D., \& Hirschberg, J. G. (1997). Bootstrapping confidence intervals for linear programming efficiency scores: With an illustration using Italian banking data. Journal of Productivity Analysis, 8(1), 19-33.

Flegg, A.T., Allen, D.O, Field, K., Thurlow, T.W. (2004). Measuring the efficiency of British universities: a multi-period data envelopment analysis. Education Economics 12(3):231-249

Glass, J.C.,McKillop D.G., \& Hyndman, N.S.(1995). Efficiency in the provision of university teaching and research: an empirical analysis of UK universities. Journal of Applied Economics 10:61-72

Johnes.J. (2006a). Data envelopment analysis and its application to the measuring of efficiency in higher Education. Economics of Education Review 25:273-288

Johnes, J. (2006b). Measuring efficiency: a comparison of multilevel modeling and data envelopment analysis in the context of higher Education. Bull Econ Res 58:75-104 
Johnes, J. (2006). Measuring teaching efficiency in higher Education: An application of data Envelopment analysis to economics graduates from UK Universities 1993. European Journal of Operational Research, 174,43-456. Johnes, G. \& Johnes,J (1995). Research funding and performance in UK university departments of economics: a frontier analysis", Economics of Education Review, 14, (3) 301-314.

Kipesha, E. F. \&Msigwa, R. (2013).Efficiency of higher learning institutions: Evidences from public universities in Tanzania. Journal of Education and Practice

Lothgren, M. (1999). Bootstrapping the Malmquist productivity index - a simulation study, Applied Economics Letters, 6(11) 707-710.

Madden, G., Savage, S. \& Kemp, S. (1997). Measuring public sector efficiency: A study of economics departments at Australian universities. Education Economics 5: 153-168.

Mooney, C.Z.,\& Duval, R.D.(1993). Bootstrapping: A nonparametric approach to statistical inference, Sage University Paper series on Quantitative Applications in the Social Sciences, vol. 07-095.Sage Publications, Newbury Park, CA.

Nsiah-Gyabaah, K. (2005a): Migration and brain drain - Implications for capacity building and institutional strengthening in the Polytechnics in Ghana, Journal of Polytechnics in Ghana, Vol. 1 No.1, pp.49-59.

Nsiah-Gyabaah, K. (2005b): Polytechnic Education in Ghana: The Past, The Present and The Future; A Paper presented at the Kick-Off Conference, NPT/UCC Project, University of Cape Coast, May 20-22.

National Council for Tertiary Education (2007): Statistical Digest, NCTE, Accra

Parteka, A \& Wolszczak-Derlacz, J. (2013). Dynamics of productivity in higher Education: cross-european evidence based on bootstrapped Malmquist indices. Journal of Productivity Analysis. 40:67-82.

Simar, L. \& Wilson, P.W.(1998). Sensitivity analysis of efficiency scores: how to bootstrap in nonparametric frontier models. Management Science $1998 ; 44(1)$.

Simar, L.\& Wilson, P.W.(1999). Estimating and bootstrapping Malmquist indices. European Journal of Operational Research. 115:459-71.

Simar L, \& Wilson P.W.( 2003). Estimation and inference in two-stage, semi- parametric models of production process. Discussion paper, Institut de Statistique, UniversitéCatholique de Louvain, Louvain-la-Neuve, Belgium.Productivity Analysis 6:137-52.

Tomkins, C. \& Green. R. (1988). An experiment in the use of data envelopment analysis for

Evaluating the efficiency of UK university departments of accounting. Financial Accountability \& Management 4: 147-164. 
Wolszczak-Derlacz, J., \& Parteka.A. (2010). Scientific productivity of public higher Education institutions in Poland - a comparative bibliometric analysis.EY - Better Governance, Warsaw.

Wolszczak-Derlacz, J., \& Parteka A. (2011). Efficiency of European public higher Education institutions: a two-stage multi country approach. Scientometrics 89:887-917

Worthington, A.C., \& Lee, B.L. (2008). Efficiency, technology and productivity change in Australian universities, 1998-2003. Econ Educ Rev 27:285-298 